\title{
Information sharing between teachers and early education programs during school entry in Norway: associations with children's school adjustment and success in the first year
}

\author{
Kyle DeMeo Cook ${ }^{1 *}$, Eric Dearing ${ }^{2}$ and Henrik Daae Zachrisson ${ }^{3}$
}

${ }^{*}$ Correspondence: demeok@bc.edu ${ }^{1}$ Lynch School of Education, Boston College, 140 Commonwealth Ave, Chestnut Hill, MA 02467, USA Full list of author information is available at the end of the article

\begin{abstract}
When children first enter school, they face simultaneous changes in their physical settings, social relationships, and learning expectations. The present study adds to the limited literature on children's transitions from early education and care into school by examining whether schools can support this transition through information sharing between elementary school teachers and early education programs. We examined information sharing as a predictor of social and academic adjustment during the first year of school for a sample of young children $(N=932)$ in Norway, where preschool is nearly universal. We find that half of first grade teachers in the sample (64\%) reported no contact with preschools; about one quarter (23\%) contacted preschools and received both general information about the preschool and specific information about the child, and smaller percentages contacted the preschools and received either general information about the program/curriculum only (8\%) or specific information about the child only (5\%). When teachers received both types of information, children were one and half times more likely to be rated as having positive social adjustment at school entry $(\mathrm{OR}=1.51, p>0.05)$ compared with other children. Mediation analyses revealed significant indirect links between this form of information sharing, children's initial social and academic adjustment, and five academic and social outcomes midyear in first grade. When initial adjustment was accounted for, we also found a slight negative effect of contact, suggesting that not all contact may be equally positive for children.
\end{abstract}

Keywords: Transition practices, School readiness, Adjustment, Preschool, Elementary school, Information sharing

\section{Background}

When children first enter school, they face simultaneous changes in their physical settings, social relationships, and learning expectations (Bronfenbrenner 1979; Fabian 2002; Pianta et al. 2007; Dockett and Perry 2013; Perry et al. 2014). The extent to which children adapt to these changes successfully has implications for later academic success and social well-being (Alexander et al. 1988). While many interventions have focused on getting children ready for school, less emphasis has been paid to the discontinuity inherent 
in children moving between systems at the start of school, and the ways schools themselves can help build continuity and be "ready" for children (National Education Goals Panel 1998; Stipek et al. 2017). Thus, questions have arisen over how schools might help smooth the transition to school and best provide ecological alignment across early education and care settings and school.

Internationally, attention to these questions has grown hand-in-hand with interest in expanding children's opportunities for early education, with the assumption that transitions may be facilitated through coordination and collaboration between early educators and schools (UNICEF 2012). Yet, there is limited empirical literature on which policy and practice might be guided. In the present study, we aimed to add to this limited literature by examining information sharing practices between early education centers and elementary school teachers in Norway, a country in which high-quality early education is now nearly universal. Specifically, we were interested in whether information sharing is associated with children's initial adjustment and their social and academic success in the first year of school.

\section{The transition to school and early development}

Although children all over the world start formal schooling at slightly different ages (generally between four and seven), this time period is developmentally meaningful time for young children, as it coincides with important cognitive changes, when basic literacy and numeracy skills are learned setting the stage for later school success (Alexander et al. 1988). Moreover, at school entry, children are expected to adjust both socially and academically, showing conventional academic skills such as understanding literacy and numeracy, and displaying appropriate social and behavioral skills including social competence and problem solving skills (Belsky and MacKinnon 1994). Yet, research evidence spanning countries with varying education contexts has shown that the transition to school is a challenging time for children and families (e.g., Cowan et al. 2005; Dockett and Perry 2013; Perry et al. 2014; Fabian 2002; Rimm-Kaufman et al. 2000; Margetts 2007).

In addition to foundational academic skills that are built, early school experiences shape children's attitudes about school and set their academic trajectories (Entwisle and Alexander 1993; Ladd et al. 2000; Ladd and Price 1987; Pianta et al. 2003). It is not surprising, then, that successful early school experiences are predictive of later school success, making the transition to school an important launching point for children.

\section{Models for successful transitions into school: from theory to practice}

When considering the important role sharing information across elementary school and early education can play in the transition, it is important to take a systems view of the transition to school. The Developmental Ecological Transition to Kindergarten model emphasizes that successful transitions are embedded in interacting systems that rely on connections among children, families, and schools (Rimm-Kaufman and Pianta 2000). While some of these connections often operate "horizontally" across contexts (e.g., home-school communication during the first year of school), others operate "vertically" (e.g., preschools teachers reaching out to elementary school teachers in the year prior to children entering school or elementary school teachers reaching back) (Kagan 
and Tarrant 2010; Kagan and Kauerz 2007; Rimm-Kaufman and Pianta 2000). Within this model, a healthy transition ecology provides regular communication and flexibility among and across the child's contexts, and unhealthy transition ecologies lack communication and support thereby creating or exacerbating discontinuities during the transition into school (Rimm-Kaufman and Pianta 2000).

Scholars, practitioners, and policymakers have, in fact, begun to conceptualize the early school years as a continuum from preschool through third grade and have called for an aligned and coordinated approach to education during these early years (Bogard and Takanishi 2005; Kagan and Tarrant 2010; Kagan and Kauerz 2007). The transition from early education settings into formal school settings is recognized as a pivotal point in the continuum, as it is common when children physically change environments and systems, with preschools and elementary schools often following different philosophies, policies, and regulations (Bogard and Takanishi 2005; Kagan and Tarrant 2010). Nonetheless, coordination and alignment between preschool and elementary school likely remains an exception. In a small study looking at teacher's perceptions of the transition activities within the context of an intervention in the United States, Pianta and colleagues found that general visits of preschoolers and their teachers to kindergarten classrooms were fairly common, but sharing information about specific children was not very common (Pianta et al. 2001). Although minimal research has looked at these vertical relationships in general, there is some evidence that kindergarten teachers spend time teaching basic materials and concepts that children have already covered and mastered in preschool (Engel et al. 2013), occupying time that could be used for more advanced material and skill building. This provides evidence that while children may be ready for school, schools may not really be "ready" for children and when information sharing does not take place, kindergarten teachers may be missing key information to meet the needs of their students.

Having more information about children as they enter school may allow teachers to have a better understanding of children's readiness for school and inform efforts to individualize instruction and connect children to appropriate learning or behavioral support services, if needed. While there is minimal research on this topic, theory, such as Vygotsky's sociocultural theory, which posits that children learn through interactions when the adults in their life are able to carefully assess their current abilities and provide scaffolding to further their learning, provides some understanding of why having more information about children at the start of school can lead to positive results (Vygotsky 1978). Moreover, alignment could allow preschool teachers to adjust their curriculum and activities to better prepare children for the academic and social expectations of formal schooling. However, it is also possible that sharing information about students may have unintended consequences, as teacher perceptions of children might be biased by other teacher's opinion, even if inaccurate (Meisels 2007). Moreover, concerns have also been made that alignment between preschools and elementary schools could lead to elementary school practices that are not considered developmentally appropriate being pushed down to preschools (Bredekamp 2010). Thus, sharing information, in and of itself, may not lead to success; the quality of the practices/information being shared and how the teachers use the information is important. Regardless, it is clear that more 
research is needed to understand the positive (and potentially negative) implications of sharing information across systems.

\section{Overview of the literature on information sharing between systems}

While there are many theoretical pieces written about the transition to school, there is minimal empirical literature (Eckert et al. 2008; Perry et al. 2014), particularly around coordination across systems and child outcomes. Past studies of school transition practices have focused on practices primarily aimed at children and families (horizontal type practices), and have indeed found small positive relationships between practices and child outcomes. For example, two studies using large-scale nationally representative samples in the United States found that more school transition practices focused on children and families (e.g., parent orientations, visits to the school) were related to prosocial skills in kindergarten (Cook and Coley 2017), and higher academic skills in the first year of school (Schulting et al. 2005).

Studies that have looked at the relationship between information sharing and children's outcomes have found some evidence to support a positive relationship, but there are limitations to these studies. In a study of preschool teachers' transition practices, researchers found that when preschool teachers shared information about curricula use or specific children with kindergarten teachers, kindergarten teachers rated those children as having more social competencies and less behavior problems in kindergarten (LoCasale-Crouch et al. 2008). Yet this study asked teachers about their transition practices generally, not whether they were done specifically for the study child in question.

Another study in Finland found that elementary school teachers' reports of cooperation with preschools on curricula and passing on written information about children were significant positive predictors of children's academic skills at school entry, but they were also the least commonly used practices (Ahtola et al. 2011). Despite this study's contribution to understanding the effects of contact around curriculum between preschools and elementary schools, Finland's school structure linking preschools directly to local elementary schools may not be applicable to many other locales (e.g., United States of America, and Norway) where preschools and elementary schools function in nonoverlapping systems.

Past literature also provides evidence that child, family, and school characteristics are related to transition practices making it important to account for them in studies about transitions (Cook and Coley 2017; Schulting et al. 2005; LoCasale-Crouch et al. 2008). In two separate studies in the US, Schulting et al. (2005) found that children from low-income families received the least transition practices, but showed the most gains from them, and LoCasale-Crouch et al. (2008) found that transition practices were more strongly related to children's functioning in kindergarten for children from families with low socioeconomic status.

\section{The transition to school in Norway}

Norway provides a relatively unique context for studying transition practices from early education through school entry. Norway has a universal and subsidized center-based early education program available from age one and attended by $96 \%$ of all children the year prior to entering formal school at age six (first grade). Early education programs 
in Norway are a separate system from the elementary school system that begins at first grade (the year children turn six). While private schools exist, 97\% of all children attend public elementary schools (Union of Education Norway 2015), with all schools covered by the same set of regulations (Directorate for Education \& Training 2008). The content of the early education programs is regulated by a national "Framework plan" (Norwegian Ministry of Education 2006), which is a broad set of guidelines governing the educational content of early education centers, comprising both pre-academic stimulation, physical activity, and arts. The framework plan also requires collaboration between the early education programs and schools in order to facilitate the transition, but does not provide specific details about how this should be done, and the requirement is not systematically enforced. Although most municipalities in Norway (who are formal owners of public child care centers and primary schools) report that they have established routines to enhance collaboration between early education programs and primary schools (Sivertsen et al. 2015), little is known about the extent to which this actually takes place, or the content of these routines (Gulbrandsen and Eliassen 2013). Consequently, a recent White Paper suggests that closer collaboration should be considered as mandatory (Ministry of Education 2016).

\section{Present study}

The present study adds to the limited literature on the developmental implications of children's transitions from early education and care into school by examining whether contact between early educators and elementary school teachers to share information predicts children's social and academic adjustment and success during the first year of school, while controlling for child, family, prior preschool, and current elementary school covariates. We examine these predictive relations in a sample of young Norwegian children, with the expectation that children would have better academic and social adjustment if their early education and elementary school teachers shared information with one another concerning the study children, specifically, as well as information concerning their respective learning environments, more generally. We expected that this contact would be positively associated with initial social and academic adjustment during the transition into elementary school as well as mid-year functioning, a few months later. Given that early education is nearly universal in Norway, a strength of the present study is the ability to address these questions in a context of early education taken to scale.

\section{Methods}

\section{Sample}

This study utilizes data from the Behavior Outlook Norwegian Developmental Study (BONDS), a longitudinal study of 1157 children from five municipalities in south-east Norway that explores multiple areas of children's development in their home and childcare/school contexts through the first year of formal schooling (first grade in Norway). Families were recruited during 5-month well-child health visits, which are public, free, and universally attended in Norway (79\% agreed to be contacted, and $60 \%$ of those initially invited accepted to participate in the study). Data collection began with a parent interview and questionnaire when the child was 6 months old, and continued through 
the child's first year of formal schooling (first grade in Norway). Data were collected through parent interviews, and questionnaires to early education providers, and questionnaires to school teachers after school start. Data on three cohorts of children who were born in 2006, 2007, and 2008 were used in this study and all children who remained in the study at first grade and had a valid elementary school ID during the final wave of data collection were included in the resulting analytic sample of $N=932$. The analytic sample included children who were $52 \%$ male, $88 \%$ Native Norwegian, $8 \%$ who were born preterm, and $3 \%$ receiving special education in first grade. Children in the sample had parents who had an average of 15 years of education, and $8 \%$ lived in single-parent households. See Table 1 for a full set of sample descriptive statistics.

\section{Measures}

\section{Teacher-center contact}

In first grade, children's first grade teachers completed a questionnaire that asked about the transition to school. Teachers reported on whether they had any contact with the study child's prior early education center at school entry (one yes/no item) and if answered yes, whether the contact was to receive general information about the program and/or if the information received was about the specific study child. These two items were used to create one categorical variable denoting whether the teacher had (1) no contact; (2) contact about general information about the program/curriculum only; (3) contact about specific information on the child only; or (4) contact about both.

\section{Initial adjustment to school}

First grade teachers reported on two separate items of how well adjusted study children were at the start of the school year, rating their social adjustment and academic adjustment separately from 1 (very poor adjustment) to five (very good adjustment). Measures of initial social and academic adjustment were only moderately correlated $(r=0.58)$ and were kept separate to assess two different constructs.

\section{Academic and social success in first grade}

First grade teachers rated children's skills and functioning in November/December of the first year of school. Communication skills were assessed through the Children's Communication Checklist (Bishop 2003), a measure of syntax, semantics, and speech through 21 items (alpha $=0.90)$. Behavioral functioning was assessed through the Social Skills Inventory Scale (SSIS), and included a Social Skills subscale (alpha $=0.96$ ), and an Externalizing Behaviors subscale (alpha $=0.92$ ). Teachers also rated children on a scale of 1-5 to assess their reading, mathematics, intellectual functioning, and general motivation in relation to their classmates (1-lowest 10\%, 2-next 20\%, 3-mid 40\%, 4almost top 20\%, 5-top 10\%) (Gresham and Elliott 2007). The reading, mathematics, and intellectual functioning scores were combined to create an academic skills rating scale (alpha $=0.93)$.

\section{Child functioning in preschool}

Children's language ability at 4 years was assessed by the British Picture Vocabulary Scale-II (Dunn et al. 1982; alpha $=0.81$ ), and children's behavior was assessed by the 
Table 1 Descriptive statistics for all variables included in models

\begin{tabular}{|c|c|c|c|}
\hline & Mean/\% & (SD) & $\%$ missing data \\
\hline \multicolumn{4}{|l|}{ Teacher-center contact } \\
\hline No contact & $64.23 \%$ & - & $9.12 \%$ \\
\hline Contact to get general information only & $7.79 \%$ & - & - \\
\hline Contact to get information about specific child only & $5.43 \%$ & - & - \\
\hline Contact to get both specific child and general information & $22.55 \%$ & - & - \\
\hline \multicolumn{4}{|l|}{ Child outcomes } \\
\hline Teacher report of initial academic adjustment at entry & 4.12 & $(0.78)$ & $6.65 \%$ \\
\hline Teacher report of initial social adjustment at entry & 4.04 & $(0.82)$ & $6.44 \%$ \\
\hline General motivation score & 3.71 & $(1.03)$ & $5.76 \%$ \\
\hline Communication skills & 2.61 & $(0.40)$ & $5.69 \%$ \\
\hline Academic skills & 3.60 & $(0.95)$ & $5.69 \%$ \\
\hline Externalizing behaviors & 1.38 & $(0.43)$ & $5.69 \%$ \\
\hline Social skills & 3.23 & $(0.41)$ & $5.69 \%$ \\
\hline \multicolumn{4}{|l|}{ Lagged dependent variables } \\
\hline British peabody picture vocabulary-age 4 & 40.17 & $(10.99)$ & $11.70 \%$ \\
\hline Child behavioral functioning-age 4 & 3.78 & $(0.88)$ & $31.22 \%$ \\
\hline \multicolumn{4}{|l|}{ Child and family characteristics } \\
\hline Male & $51.72 \%$ & - & $0.00 \%$ \\
\hline Cohort: 2006 & $38.52 \%$ & - & $0.00 \%$ \\
\hline Cohort: 2007 & $44.96 \%$ & - & - \\
\hline Cohort: 2008 & $16.52 \%$ & - & - \\
\hline Native Norwegian & $88.08 \%$ & - & $0.97 \%$ \\
\hline Western immigrant & $6.28 \%$ & - & - \\
\hline Non-western immigrant & $5.63 \%$ & - & - \\
\hline Municipality: Bamble & $11.31 \%$ & - & $16.52 \%$ \\
\hline Municipality: Drammen & $41.26 \%$ & - & - \\
\hline Municipality: Porsgrunn & $26.48 \%$ & - & - \\
\hline Municipality: Skien & $12.72 \%$ & - & - \\
\hline Municipality: Tinn & $8.23 \%$ & - & - \\
\hline Parent education (years) & 15.04 & $(2.39)$ & $0.86 \%$ \\
\hline Preterm birth & $7.77 \%$ & - & $1.93 \%$ \\
\hline Special ed services in first grade & $3.30 \%$ & - & $5.69 \%$ \\
\hline Siblings in family & $60.54 \%$ & - & $0.75 \%$ \\
\hline House deprivation score (60 months) & 0.12 & $(0.38)$ & $0.43 \%$ \\
\hline Single mom at 60 months & $8.79 \%$ & - & $7.19 \%$ \\
\hline Hours in child care at 60 months & 34.71 & $(5.85)$ & $4.83 \%$ \\
\hline \multicolumn{4}{|l|}{ Center and school characteristics } \\
\hline Preschool ped leader trained as preschool teacher & $85.20 \%$ & - & $31.87 \%$ \\
\hline Preschool center school prep activity index & 2.41 & $(0.21)$ & $31.87 \%$ \\
\hline First grade classroom climate score & 3.08 & $(0.22)$ & $5.79 \%$ \\
\hline First grade class size & 22.79 & $(8.07)$ & $6.01 \%$ \\
\hline First grade school size & 345.32 & $(132.53)$ & $7.19 \%$ \\
\hline \# Kids in first grade class with special ed services & 1.02 & $(1.74)$ & $7.08 \%$ \\
\hline
\end{tabular}

$N=932$

Teacher Report Form of the Child Behavior Checklist measuring children's externalizing behaviors, attention problems, and aggression at 4 years (Achenbach 1991; alpha $=0.93)$. 
Child and family characteristics Information about children and families included in this study as covariates was collected through parent interviews at child age 6 months, which includes the following: child's gender, child's immigrant status (Norwegian, Western-Europe, North America, and Oceania, or Non-Western-Asia, Africa, Latin America, and Turkey), parent's years of education, an index of living in poor housing conditions (dissatisfaction with housing, living in a one bedroom or smaller, and not owning home [home ownership is normative in Norway]), whether the child has siblings, whether the child was preterm at birth, whether the child's mother was single. A continuous measure of the number of hours the child was in center-based child care at age 5 years was from a telephone interview taken at approximately the child's fifth birthday, and whether the child qualified for special education services in first grade was taken from a teacher questionnaire in first grade.

Preschool center and elementary school characteristics Information on the characteristics of centers and schools was included in this study as covariates. Preschool centers employ pedagogical leaders who support school preparation activities. An indicator of whether or not the pedagogical leader is trained as an early childhood teacher is included. In addition, the pedagogical leader reported on how much (a lot, some, a little) they engaged their children in eighteen different school preparation activities that they engaged their children in during the preschool year (e.g., language skills, motor development, activities to get children familiar with the social and physical environment of the school setting, and the rules of the school setting). These items were summed to create a school preparation index (alpha $=0.64)$.

First grade teachers reported on class size, school size, and the number of children in their classrooms receiving special education services. Additionally, the climate of the first grade classroom was assessed through teacher report of fourteen items (e.g., classroom is a calm working environment, students are attentive to the teacher, students are interested and active during class), with a report of not true to very true (1-4), $($ alpha $=0.81)$.

\section{Analytic plan}

Prior to analysis, the dataset was analyzed for missing data (see Table 1 for variable level missing data percentages). To account for missing data, we employed multiple imputation-20 imputations-using chained equations in Stata 14 (Royston 2005). In order to account for children in the same schools in first grade (110 schools), a Huber-White standard error adjustment was used to account for clustering using the child's school identifier in all models. Since prior research using the BONDS data has revealed important differences among cohorts of children and across municipalities, indicators of both were also included (Zambrana et al. 2015).

We first conducted ordinal logit models using the imputed datasets to assess whether contact between teachers and centers was associated with initial academic and social adjustment in first grade. Separate models were run to assess each outcome (academic adjustment and social adjustment) with the categorical contact variable as the main predictor of interest. Measures of children's prior functioning at 4 years old were included in the models as well as a rich array of children, family, center, and school characteristics. 
Next, five separate models were run with teacher contact predicting five separate child outcomes (academic skills, communications skills, general motivation, externalizing behaviors, and social skills) a few months into first grade. An ordinal logit model was run for the model predicting the ordinal general motivation outcome, and ordinary least squares regression models (OLS) were run for the other four continuous outcomes. Each model included the full set of child, family, preschool, and elementary school characteristics, controlled for child prior functioning at 4 years old, and initial social and academic adjustment at school entry (see Table 1 for all covariates included in the models), and were conducted using the imputed data.

Finally, to assess whether the association between teacher contact and children's success in first grade was mediated by the more proximal mechanism of initial academic and/or social adjustment to school, direct and indirect effects were estimated within a structural equation modeling framework (Preacher and Hays 2008). For these models, full information maximum likelihood estimation was used to account for missing data, and analysis was conducted on the original raw dataset. Using Stata 14, all associations displayed in Fig. 1 were estimated simultaneously, including direct and indirect effects. In these models, we also included the covariate set estimated in our regression models, and standard errors were adjusted for nesting within schools.

\section{Results}

\section{Descriptive results}

Table 1 provides descriptive statistics for all variables used in analyses. Of particular note for the present study, more than half of the first grade teachers (64\%) reported no contact with preschools; about one quarter $(23 \%)$ contacted preschools and received both general and specific information, and smaller percentages contacted the preschools and received either general information only (8\%), or specific information about the child only $(5 \%)$. Also of note when exploring these variables descriptively is that, although teacher assessments of initial adjustment were fairly skewed, teachers reported most children having good or very good adjustment, teacher-reported assessments of social

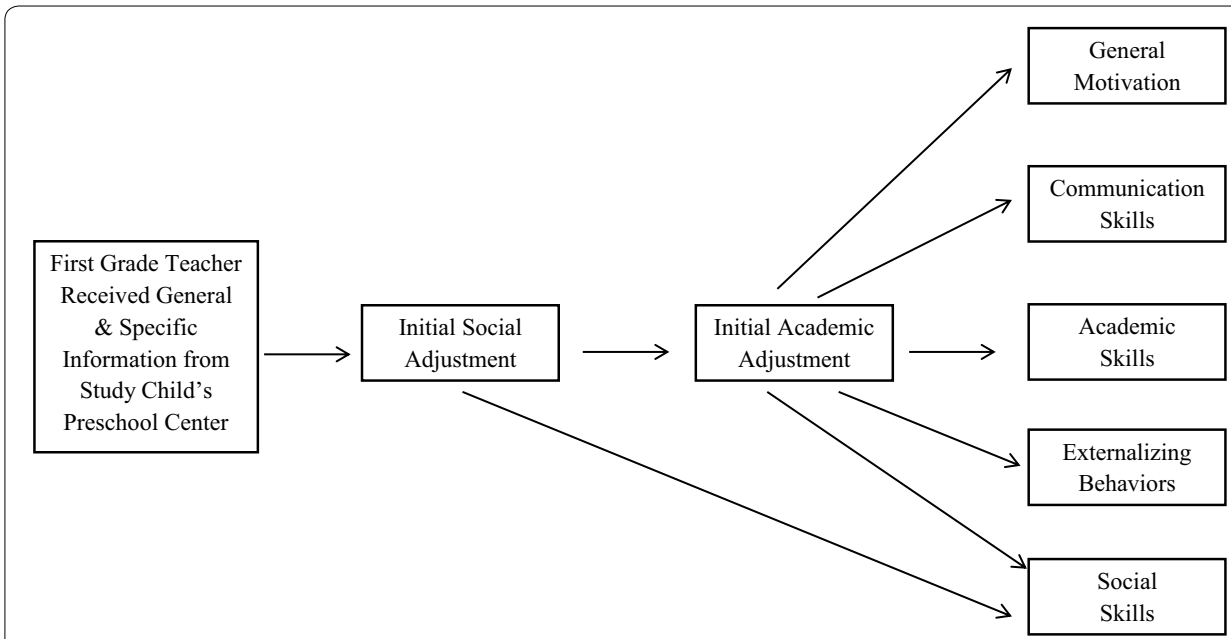

Fig. 1 Hypothesized teacher-center contact and child outcomes mediation model 
and academic functioning better approximate a normal distribution. However, the statistical models used in the study are robust to deviations from the normal distribution (Boomsma and Hoogland 2001).

\section{Teacher-center contact and children's adjustment to school: direct associations}

As a first step in our analytic plan, we used regression to examine associations between teacher contact and initial adjustment (Table 2). Children with teachers who contacted their early education centers and received both types of information (about specific children and curriculum) were one and half times more likely to receive higher ratings of positive social adjustment at school entry $(\mathrm{OR}=1.51, p>0.05)$. There was no statistically significant difference between information sharing and initial positive social adjustment for children who only had one or the other type of information sharing compared to children who had no information sharing reported for them. We also did not find a direct association between information sharing and ratings of children's initial academic adjustment. Similarly, there were no significant direct associations between information sharing and the mid-year assessments of social and academic functioning (academic skills, general motivation, communication skills, externalizing behaviors, and social skills) (Table 2). However, given strong associations between initial social adjustment and the other outcomes, we examined potential indirect (mediated) links from contact to social adjustment to the other outcomes (see Table 3 for correlations).

\section{Teacher-center contact and children's adjustment to school: indirect associations}

As a follow up to our regression models, we examined pathways of mediation (Fig. 1). Specifically, we used structural equation modeling to simultaneously examine direct and indirect associations between teacher-center contact and later adjustment via initial social adjustment. For these mediation analyses, we examined whether teacher contact was indirectly related to initial academic adjustment via initial social adjustment and, in turn, whether initial academic adjustment predicted later adjustment (i.e., academic skills, general motivation, communication skills, externalizing behaviors, and social skills). From these models, direct effects are displayed in Table 4 and indirect (i.e., mediation) effects are displayed in Table 5.

Consistent with the regression models, contact about both general program/curriculum information and specific information on the child was positively predictive of initial social adjustment $(0.16, p<0.05)$. In turn, initial social adjustment was strongly and positively related to higher initial academic adjustment $(0.50, p<0.001)$, even when controlling for child, family, preschool, and school characteristics. Moreover, as reported in the first column of Table 5, the indirect effect from contact between teachers to social adjustment and, in turn, to academic adjustment was statistically significant $(0.08$, $p<0.05)$. In addition, as indicated in Table 4 , initial social adjustment positively predicted mid-year assessments of social skills, providing a significant (see Table 5) indirect link from teacher contact to initial social adjustment to mid-year social skills.

Although initial academic adjustment was only indirectly linked with information sharing, this initial academic adjustment indicator positively predicted general motivation (0.77, $p<0.001)$, communication skills $(0.15, p<0.001)$, academic skills $(0.15, p<0.001)$, and social skills $(0.09, p<0.001)$, and negatively predicted externalizing behaviors $(-0.14$, 


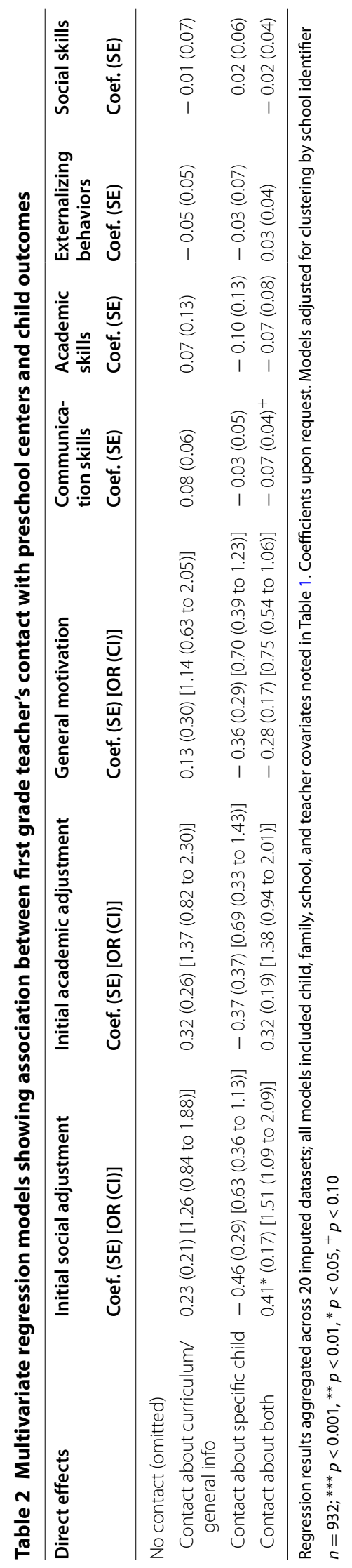


Table 3 Correlations among child outcomes

\begin{tabular}{lrrrrrrr}
\hline & $\mathbf{1}$ & $\mathbf{2}$ & $\mathbf{3}$ & $\mathbf{4}$ & $\mathbf{5}$ & $\mathbf{6}$ & $\mathbf{7}$ \\
\hline 1. Academic adjustment at entry & 1.00 & & & & & & \\
2. Social adjustment at entry & 0.58 & 1.00 & & & & & \\
3. General motivation score & 0.58 & 0.29 & 1.00 & & & & \\
4. Communication skills & 0.35 & 0.22 & 0.45 & 1.00 & & \\
5. Academic skills & 0.54 & 0.30 & 0.81 & 0.52 & 1.00 & \\
6. Externalizing behaviors & -0.36 & -0.25 & -0.41 & -0.23 & -0.28 & 1.00 & \\
7. Social skills & 0.51 & 0.42 & 0.55 & 0.38 & 0.43 & -0.72 & 1.00 \\
\hline
\end{tabular}

All correlations significant at $p>0.05$

$p<0.001$ ) (see Table 4). Moreover, the associations between initial academic adjustment and the later five outcomes provided significant indirect effects (as detailed in Table 5) linking initial social skills with the five later outcomes. With caveat that we did not originally predict that initial academic adjustment would mediate links between social adjustment and the other outcomes, this pathway ultimately provided a two-step pathway of mediation from contact to social adjustment to academic adjustment and, finally, to the mid-year outcomes. In Fig. 2, we detail these pathways of association. The results for the structural equation model also showed that the positive benefits for information sharing were for children who received both types of information sharing, and outcomes for children who had only one type of information sharing reported by their teachers were not statistically different than children who had no information sharing.

Finally, it is worth noting that controlling for the intermediary effects of social and academic adjustment at school entry led to negative suppression effects for associations between teacher information sharing and two of the outcomes, general motivation and communication skills. In other words, once adjusting for the indirect positive links between teacher contact and these outcomes that were relayed via the initial adjustment indicators, more teacher contact predicted less favorable outcomes in these two domains.

\section{Discussion}

In the present study, we examined Norwegian children's early social and academic adjustment in elementary school, finding that information sharing between preschool teachers and elementary school teachers about specific children and preschool curriculum may improve children's initial adjustment in elementary school. Additionally, our findings indicate that this initial adjustment advantage may lead to broader social and academic gains during the first year of school.

Specifically, we found that children have more positive social adjustment at the start of school if their teachers in early elementary school connect with preschool teachers for general information about the preschool program children attended and specific information about the child. This social adjustment, in turn, was associated with better early academic adjustment. Moreover, we found evidence of indirect positive relations between teacher contact and children's social and academic skills mid-year, with these relations mediated through positive social and academic adjustment at the beginning of the year. We interpret these correlations within the present cumulative knowledge on transitions, limited as it may be, and offer potential implications for policy and practice. 


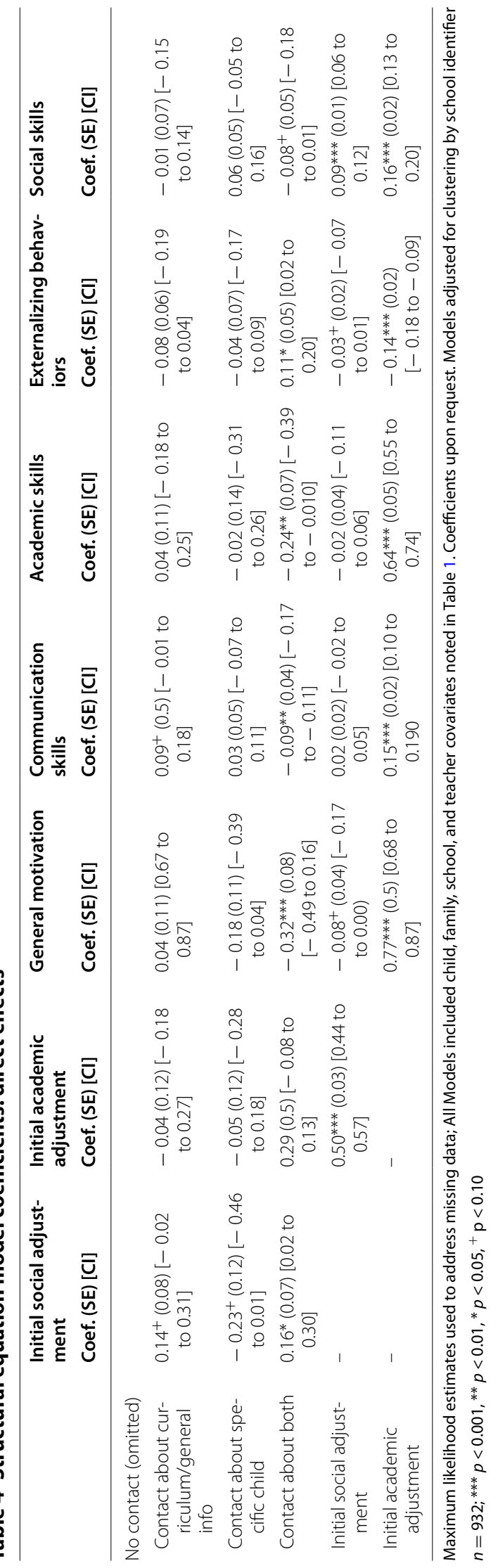




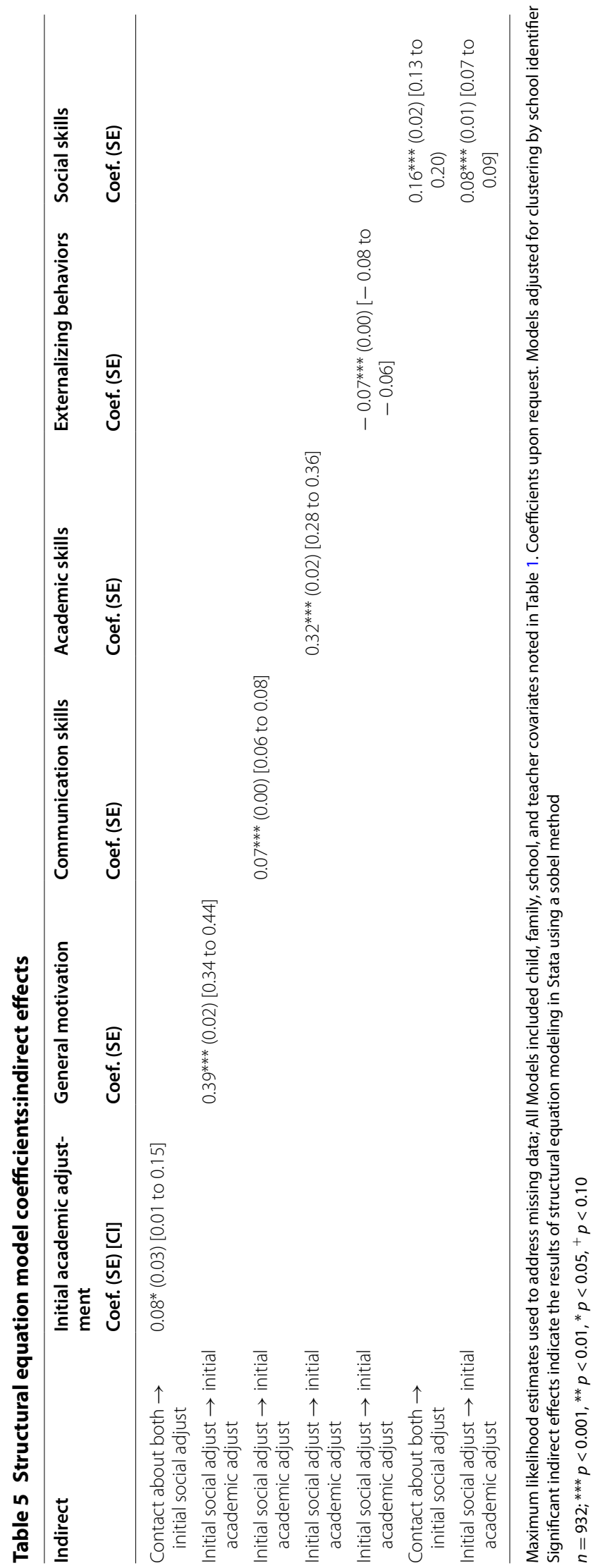




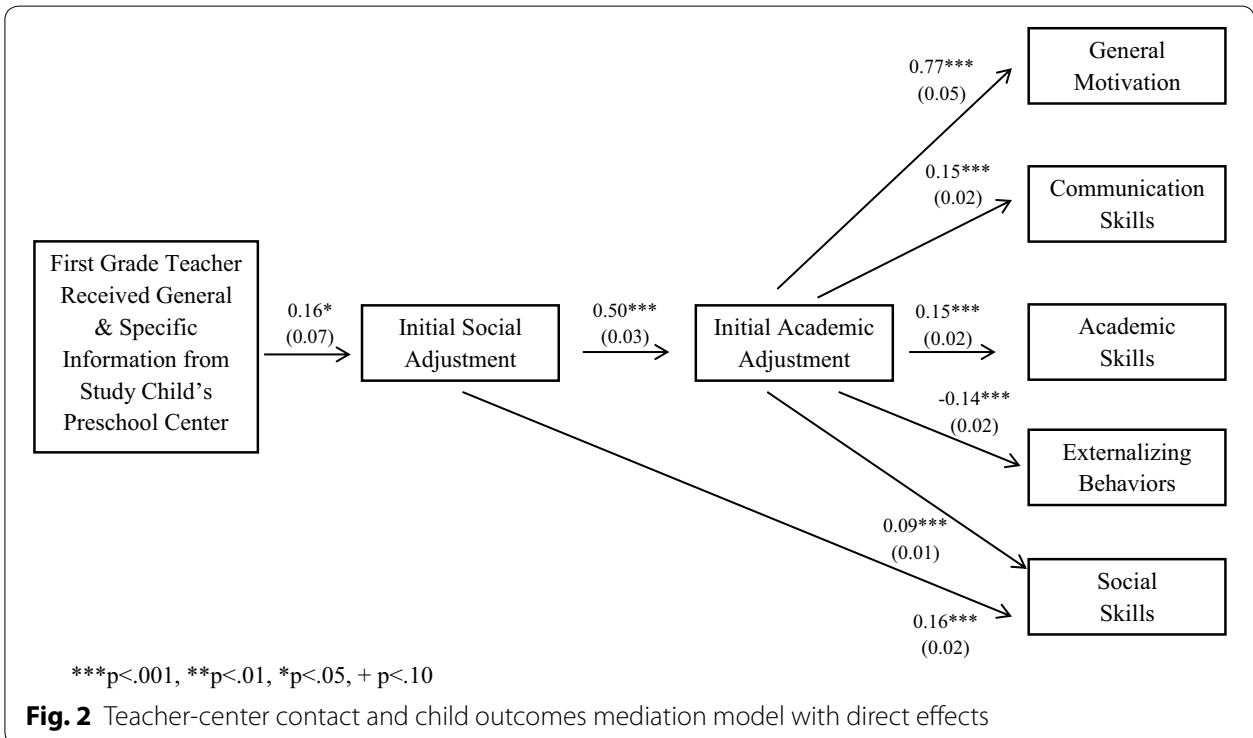

\section{The positive role of information sharing during the transition to school}

Theoretical models of positive school transitions highlight the importance of communication across the contexts the child is transitioning between, with an emphasis on the value of this communication for vertical alignment across preschool and elementary school classrooms (Rimm-Kaufman and Pianta 2000). The results of the present study are, in fact, consistent with limited evidence on information sharing between preschool and elementary school teachers. In the two studies on this topic, of which we are aware, information sharing about curricula has been associated with positive social behaviors and better academic skills at school entry (Ahtola et al. 2011; LoCasale-Crouch et al. 2008). The present study adds to this work by demonstrating that information sharing that is specific to each child may also be critical.

Theoretically, having more information about children as they enter school may allow elementary school teachers to have a better understanding of the child's readiness for school and inform their ability to individualize instruction and connect children to appropriate services (if needed), in turn producing better social and academic outcomes for children. Some research has suggested that kindergarten teachers may spend too much time on content that was already mastered in preschool and temper children's growth (Engel et al. 2013). Sharing information between preschools and elementary schools may provide alignment of curriculum and high-quality learning experiences, potentially capitalizing on gains made in preschool and allowing elementary schools to build upon, rather than repeat, what was learned in preschool, as well as provide teachers with information needed to tailor children's experiences to their needs (Bogard and Takanishi 2005; Engel et al. 2013).

\section{When information sharing may not be beneficial}

However, we also found that once adjusting for the indirect positive links between teacher contact and the five outcomes (as relayed via the initial adjustment indicators), more teacher contact predicted less favorable outcomes. In other words, there appeared 
to be both positive and negative associations between teacher contact and child outcomes. From a conceptual and statistical perspective, this result helps explain why the direct effect of contact was null for the five outcomes; that is, the positive and negative associations cancel one another out prior to estimating the indirect positive effects of contact via initial adjustment.

Conceptually, a potential explanation is that transitions practices are not just about what teachers do, but how they do it: quality of the contact likely matters. There may be some helpful ways of connecting vertically and some unhelpful ways, and our measure seems to be picking up a little of both. In addition, it is possible that information sharing is not happening for all children equally and may be happening more for children who have behavioral or academic challenges. If teachers have this information at the start of school, their assessments of the children's strengths and weaknesses may be biased as children enter and potentially continue through the school year. We did, however, include prior behavioral functioning in our models in order to help account for this possibility.

Although this is an important avenue for future research to pursue, we speculate that the positive effects of contact were likely due to those teachers who used information sharing as a tool for tailoring their teaching practices to better support individual children's strengths and needs, but the negative effects may have been due to teachers' perceptions of students being negatively biased by learning of children's earlier learning or behavior struggles. More training and professional development is likely needed to help teachers understand the information that they receive about children (e.g., from preschools, parents, direct assessments) and how to utilize the information to inform their instruction and interactions with the child in a positive direction. In addition, more research is needed in the future to better understand how teachers are using information they are receiving about children at the start of school.

\section{Implications for policy and practice}

Children enter school facing large discontinuities between the contexts they are leaving and the new ones they are entering. Our findings suggest that when teachers know more about the children and the contexts they are coming from, the children may be better socially adjusted at the start of school. In turn, the children who show better signs of positive social adjustment at the start of school may also exhibit significantly better academic skills and positive behaviors throughout the first year of school. There are a few possible explanations for this. First, teachers who receive information about the children before school starts can use this information to tailor instruction and guide their own behaviors and interactions with the specific child. This helps the child as they enter school, making them feel more comfortable and able to gain more from the academic experiences being provided in the classroom. There is some evidence from past research that when teachers do not have information about what children know when they enter, school time is wasted on materials that were already covered, making it more efficient when they have the information they need. However, in order to get the most out of the information they receive, it is likely that more professional development and training is needed in this area. 
Our findings on the potential value of information sharing, however, must be juxtaposed with the fact that more than half of children had first grade teachers who reported no contact with their preschool teachers, and our positive findings only held if teachers received both types of information (about the program/curricula and specific study child). One possible reason for the lack of contact between first grade teachers and preschool teachers in our sample is that schools in Norway, as do schools in many other nations, often assign children to their first grade classes late in the spring term preceding school entry. Thus, many teachers do not have time to establish contact with the preschools. This confirms limited past research that kindergarten teachers may find it challenging to collaborate and meet with preschool teachers around specific children before school entry (Pianta et al. 2001).

Some research has suggested that formal connections between preschools and elementary schools (e.g., preschools in elementary school buildings, shared oversight) may aid in the process of connecting across these systems (Ahtola et al. 2011; Desimone et al. 2004; Pianta et al. 2001; Wildenger and McIntyre 2012), which was not the case in this study. In addition, the results may be mixed if teachers and preschools are only connecting about a specific child when there is a behavioral or academic concern and then the positive benefits are not seen. However, all models do adjust for prior academic and social functioning in order to account for this possibility.

Since the first grade teacher is the reporter of the predictor and outcomes in the study, another possible explanation is that if a teacher receives information about the child before school entry, they also rate the child more positively on social adjustment. In turn, if the teacher receives more negative information about the child, they may focus on the child's weaknesses and suggested problems, rather than their strengths in their early interactions and subsequent ratings of their skills and behaviors. While this could be a methodological limitation of the study, it is also a helpful consideration for practice. Past theory and research posited that teacher's perceptions of children (whether true or not) are predictive of children's outcomes (Rosenthal and Jacobson 1968). If teachers have better perceptions of children after receiving information about them, this can also be positive. The results of this study also support the importance of initial social adjustment and its predictive relation to success in the first year of school.

\section{Limitations}

The present study adds to the limited cumulative knowledge on school transitions and extends the current literature by examining information sharing about the specific study child and looking at both immediate child outcomes at school entry as well as a few months into the first year to school to understand this mediated pathway. However, a few limitations and caveats are worth noting. First, while we employed useful statistical covariates to address potential sources of bias, including child behavioral and achievement indicators prior to school entry, it is important to underscore the fact that this study was correlational. It is important that future work go further, perhaps experimentally, in probing the causal hypothesis that improved communication and information sharing can improve child outcomes. Second, despite the fact that we were able to examine both general information sharing about the preschool program and information sharing specific to the study child (the latter being exceptionally rare in the empirical 
literature), we were not able to examine the nature, exact topic, or quality of transition communication. Additional research is needed to gain a deeper understanding of the ways in which teachers engage in these conversations, the information they receive, and the best practices for using this information as children enter school. As noted above, quality of contact likely matters. More research is needed to examine the ways in which communication across systems can yield the best results for children and lead to positive adjustment. In addition, this study only provided reports from the elementary school teacher. To truly understand the relationships around information sharing across systems, future research must also take into account the ways this information sharing may affect practices at the preschool level as well. Third, it should be noted that our analyses relied heavily on first grade teacher reports, for both data about transition communication and first grade child outcomes, with the initial academic and social adjustment measures only including one item each. Future work employing multiple reporters and more comprehensive measures is needed for purposes of triangulation as well as ruling out shared method variance concerns. Last, children in the sample are nested in schools and likely in classrooms, yet only school (not classroom/teacher) identifiers are available from the data collectors. All models adjust for clustering at the school level, but may show some bias since they do not take into account that children may be in different classrooms within schools. Nonetheless, in an area that has, to date, received much too little empirical attention, our study provides novel evidence on the potential value of vertical communications between teachers during children's transition from preschool to school.

\section{Conclusions}

The present study provides support for the importance of initial adjustment to school and the value of information sharing between preschool and elementary school teachers for promoting initial adjustment. The results are consistent with the expectation that information sharing across systems may help minimize discontinuities and ecological disruptions otherwise inherent in early transitions, thereby supporting children's early academic and social functioning. Building from these promising findings, research is needed to identify the mechanisms (e.g., how, why, when, about what) by which teacher communication can improve children's adjustment to school, and how teachers can be supported to engage in these practices effectively.

Authors' contributions

All authors were involved in the conceptualization, design, and planning of the study and analysis. KDC primarily undertook the data analysis and manuscript drafting. ED supported the analysis and interpretation and wrote parts of the manuscript. HDZ was part of the original study design, data collection, and data cleaning and supported data analysis and interpretation and manuscript writing. All authors read and approved the final manuscript.

\section{Author details}

${ }^{1}$ Lynch School of Education, Boston College, 140 Commonwealth Ave, Chestnut Hill, MA 02467, USA. ${ }^{2}$ Boston College, Chestnut Hill, MA, USA. ${ }^{3}$ The Norwegian Center for Child Behavioral Development \& Center for Educational Measurement at the University of Oslo, Oslo, Norway.

Competing interests

The authors declare that they have no competing interests.

Ethics approval and consent to participate

The present work is part of the "Behavioral Outlook: Norwegian Developmental Study" (BONDS). The study is approved by the Regional Ethics Committee and the Data inspectorate in Norway, and participants have signed informed consent forms. There are no ethical conflicts regarding the present work, and the authors are authorized by the leader group of BONDS to publish the work. 


\section{Funding}

This study was supported by The Norwegian Council of Research (NCR), Grant No. 212260. The second author was partially supported by NCR Grant No. 234828. The funding body played no role in the study design, collection, analysis, data interpretation, or manuscript writing.

\section{Publisher's Note}

Springer Nature remains neutral with regard to jurisdictional claims in published maps and institutional affiliations.

Received: 12 December 2016 Accepted: 16 November 2017

Published online: 28 November 2017

\section{References}

Achenbach, T. M. (1991). Manual for the child behavior checklist/4-18 and 1991 profile (p. 288). Burlington, VT: Department of Psychiatry, University of Vermont.

Ahtola, A., Silinskas, G., Poikonen, P.-L., Kontoniemi, M., Niemi, P., \& Nurmi, J.-E. (2011). Transition to formal schooling: Do transition practices matter for academic performance? Early Childhood Research Quarterly, 26, 295-302.

Alexander, K. L., Entwisle, D. R., Blyth, D. A., \& McAdoo, H. P. (1988). Achievement in the first 2 years of school: Patterns and processes. Monographs of the Society for Research in Child Development, 53, 1-157.

Belsky, J., \& MacKinnon, C. (1994). Transition to school: Developmental trajectories and school experiences. Early Education and Development, 5(2), 106-119.

Bishop, D. V. M. (2003). The children's communication checklist: CCC-2. London: Harcourt Assessment.

Bogard, K., \& Takanishi, R. (2005). Pk-3: An aligned and coordinated approach to education for children 3 to 8 years old (pp. 1-24). XIX(III): Social Policy Report.

Boomsma, A., \& Hoogland, J. J. (2001). Structural equation models: Present and future. A Festschrift in honor of Karl Jöreskog. The Robustness of LISREL Modeling Revisited, 2(3), 139-168.

Bredekamp, S. (2010). Aligning curriculum and teaching: A child-focused approach. In S. L. Kagan \& K. Tarrant (Eds.), Transitions for young children. Baltimore, MD: Paul H. Brookes Publishing.

Bronfenbrenner, U. (1979). The ecology of human development: Experiments by design and nature. Cambridge, MA: Harvard University Press.

Cook, K. D., \& Coley, R. L. (2017). The use of school transition practices and children's social adjustment and academic outcomes in kindergarten. Journal of Educational Psychology, 109(2), 166-177. https://doi.org/10.1037/edu0000139.

Cowan, P. A., Cowan, C. P., Ablow, J. C., Johnson, V. K., \& Measelle, J. R. (2005). The family context of parenting in children's adaptation to elementary school. Mahwah, NJ: Lawrence Erlbaum.

Desimone, L., Payne, B., Fedoravicius, N., Henrich, C., \& FinnStevenson, M. (2004). Comprehensive school reform: An implementation study of preschool programs in elementary schools. Elementary School Journal, 104, 369-389.

Directorate for Education \& Training. (2008). A brief introduction to the Norwegian Directorate for Education and Training. Retrieved from http://www.udir.no/Stottemeny/ English/A-brief-introduction-to-the-Norwegian-Directorate-for-Education-and-Training/.

Dockett, S., \& Perry, B. (2013). Trends and tensions: Australian and international research about starting school. International Journal of Early Years Education, 21(2-3), 163-177. https://doi.org/10.1080/09669760.2013.832943.

Dunn, L. M., Dunn, L. M., Whetton, C., \& Pintilie, D. (1982). British Picture Vocabulary Test (2nd ed., p. 1997). London: NFER-Nelson.

Eckert, T.L., McIntyre, L.L., DiGennaro, F.D., Arbolino, L.A., Perry, L.J., \& Begeny, J.C. (2008). Researching the transition to kindergarten for typically developing children: A literature review of current processes, practices and programs. In. D. H. Molina (Ed.), School psychology: 21st century issue and challenges (pp. 235-252). Hauppauge, NY: Nova Sciences.

Engel, M., Claessens, A., \& Finch, M. A. (2013). Teaching students what they already know? The (mis)alignment between mathematics instructional content and student knowledge in kindergarten. Educational Evaluation and Policy Analysis, 35(2), 157-178.

Entwisle, D. R., \& Alexander, K. L. (1993). Entry into school:The beginning school transition and educational stratification in the United States. Annual Review of Sociology, 191(1), 401-423.

Fabian, H. (2002). Children starting school. London: Fulton.

Gresham, F., \& Elliott, S. N. (2007). Social skills improvement system (SSIS) rating scales. San Antonio, TX: Pearson Education Inc.

Gulbrandsen, L., \& Eliassen, E. (2013). Kvalitet i barnehager. Rapport fra en undersøkelse av strukturell kvalitet høsten 2012. (Child care quality. Report from a survey of structural quality, fall of 2012) Rapport 1/2013, NOVA.

Kagan, S. L., \& Kauerz, K. (2007). Reaching for the whole. Integration and alignment in early education policy. In R. C. Pianta, M. J. Cox, \& K. L. Snow (Eds.), School readiness and the transition to kindergarten in the era of accountability (pp. 11-30). Baltimore, MD: Brookes.

Kagan, S. L., \& Tarrant, K. (2010). Integrating pedagogy, practice and policy: A transition agenda. In S. L. Kagan \& K. Tarrant (Eds.), Transitions for young children: Creating connections across early childhood systems (pp. 33-44). Baltimore: Brookes.

Ladd, G. W., Buhs, E. S., \& Seid, M. (2000). Children's initial sentiments about kindergarten: Is school liking an antecedent of early classroom participation and achievement? Merrill-Palmer Quarterly-Journal of Developmental Psychology, 46(2), 255-279.

Ladd, G. W., \& Price, J. M. (1987). Predicting children's social and school adjustment following the transition from preschool to kindergarten. Child Development, 58(5), 1168-1189. 
LoCasale-Crouch, J., Mashburn, A. J., Downer, J. T., \& Pianta, R. C. (2008). Pre-kindergarten teachers' use of transition practices and children's adjustment to kindergarten. Early Childhood Research Quarterly, 23, 124-139.

Margetts, K. (2007). Preparing children for school-benefits and privileges. Australian Journal of Early Childhood, 32(2), 43-50.

Meisels, S. (2007). Accountability in early childhood: No easy answers. In R. C. Pianta, M. J. Cox, \& K. L. Snow (Eds.), School readiness and the transition to kindergarten in the era of accountability (pp. 31-47). Baltimore, MD: Brookes.

Ministry of Education. (2016). Meld. St. 19 (2015-2016). Tid for lek og læring. Bedre innhold I barnehagen. [White Paper 19 (2015-2016) Time for play and learning. Better content in early education]. Retrieved Apr 4, 2016, from https://www. regjeringen.no/no/dokumenter/meld.-st.-19-20152016/id2479078/.

National Education Goals Panel. (1998). Ready schools. Washington, DC: U.S. Government Printing Office.

Norwegian Ministry of Education. (2006). Rammeplan for barnehagens innhold og oppgaver [Framework plan for content and duties in kindergartens]. Retrieved from http://www.regjeringen.no/nb/dep/kd/dok/lover_regler/reglement/2006/rammeplan-for-barnehagens-innhold-og-opp.html?id=278626.

Perry, B., Dockett, S., \& Petriwskyj, A. (2014). Transitions to school: International research, policy and practice. New York, NY: Springer.

Pianta, R. C., Cox, M. J., \& Snow, K. L. (2007). School readiness and the transition to kindergarten in the era of accountability. Baltimore, MD: Brookes.

Pianta, R. C., \& Kraft-Sayre, M. (2003). Successful kindergarten transition: Your guide to connecting children, families, and schools. Baltimore: Brookes.

Pianta, R. C., Kraft-Sayre, M., Rimm-Kaufman, S., Gercke, N., \& Higgins, T. (2001). Collaboration in building partnerships between families and schools: The National Center for Early Development and Learning's Kindergarten Transition Intervention. Early Childhood Research Quarterly, 16(1), 117-132.

Preacher, K. J., \& Hays, A. F. (2008). Asymptotic and resampling strategies for assessing and comparing indirect effects in multiple mediator models. Behavior Research Methods, 40(3), 879-891.

Rimm-Kaufman, S. E., \& Pianta, R. C. (2000). An ecological perspective on the transition to kindergarten: A theoretical framework to guide empirical research. Journal of Applied Developmental Psychology, 21, 491-511.

Rimm-Kaufman, S. E., Pianta, R. C., \& Cox, M. J. (2000). Teachers' judgements of problems in the transition to kindergarten. Early Childhood Research Quarterly, 15, 147-166.

Rosenthal, R., \& Jacobson, L. (1968). Pygmalion in the classroom: Teacher expectation and pupils' intellectual development, by Robert Rosenthal. Rinehart and Winston: Lenore Jacobson.

Royston, P. (2005). Multiple imputation of missing values: Update of ice. Stata Journal, 5, 527-536.

Schulting, A. B., Malone, P. S., \& Dodge, K. A. (2005). The effect of school-based kindergarten transition policies and practices on child academic outcomes. Developmental Psychology, 41, 6.

Sivertsen, H., Haugum, M., Haugset, A.S., Carlsson, E., Nilsen, R.D., \& Nossum, G. (2015). Spørsmål til Barnehage-Norge 2014. (Questions for child care centers in Norway) Rapport 1/2015, Trøndelag Forskning og Utvikling.

Stipek, D., Clements, D., Coburn, C., Franke, M, \& Ferran, D. (2017). PK-3: What does it mean for instruction? Social Policy Report 30(2). Society for Research in Child Development.

Unicef. (2012). School readiness and transitions: A companion to the child friendly schools manual. Unicef. Retrieved from http://www.unicef.org/publications/files/CFS_School_Readiness_E_web.pdf.

Union of Education Norway. (2015). Nøkkeltall for grunnskolen t.o.m. skoleåret 2013/14. Faktaark 2014:1. [Key numbers for elementary school including the academic year 2013/2014. Fact report 2014:1]. Retrieved Apr 4, 2016, from https:// www.utdanningsforbundet.no/upload/Publikasjoner/Faktaark/Faktaark\%202014/Faktaark_2014.01.pdf.

Vygotsky, L. (1978). Interaction between learning and development. In Gauvian \& Cole (Eds.), Readings on the development of children (pp. 34-40). New York: Scientific American Books.

Wildenger, L. K., \& McIntyre, L. L. (2012). Investigating the relation between kindergarten preparation and child sociobehavioral school outcomes. Early Childhood Education Journal, 40, 169-176.

Zambrana, I. M., Dearing, E., Nærde, A., \& Zachrisson, H. D. (2015). Time in ECEC and language competence in Norwegian 4-year-old girls and boys. European Early Childhood Education Research Journal., 25, 4.

\section{Submit your manuscript to a SpringerOpen ${ }^{\circ}$ journal and benefit from:}

Convenient online submission

- Rigorous peer review

- Open access: articles freely available online

- High visibility within the field

Retaining the copyright to your article

Submit your next manuscript at $\boldsymbol{\Delta}$ springeropen.com 